\title{
ANALISIS VARIASI STRUKTUR SERAT RAMI KOMPOSIT MATRIK EPOKSI TERHADAP KEKUATAN UJI BALISTIK DAN BENDING
}

\author{
Reinaldi Teguh Setyawan* dan Slamet Riyadi \\ Politeknik Baja Tegal (Jurusan Teknik Mesin, Politeknik Baja Tegal, Indonesia) \\ J1. Raya Barat Dukuhwaru, Jatibarang-Slawi Km. 7, Kab Tegal Telp. (0283) 6196309 \\ "Email: aldyteguh56@yahoo.com
}

\begin{abstract}
Abstrak
Tujuan penelitian ini untuk mengetahui kekuatan uji balistik dan bending terhadap variasi struktur serat rami. Bahan yang digunakan dalam penelitian ini adalah Resin epoksi tipe General Purpose (Bisphenol A-Epichlorohydrin) dan Hardener tipe General Purpose (Polyaminoamide), Silikon Karbida dengan ukuran 120 dan Serat rami. Alat yang digunakan dalam penelitian ini yaitu: gunting, cetakan spesimen dengan ukuran untuk cetakan pengujian bending adalah $5 \mathrm{~cm} \times 19 \mathrm{~cm}$ dan cetakan pengujian balistik $20 \mathrm{~cm} \times 20 \mathrm{~cm}$, mixer, grease, gelas ukur, jangka sorong, pistol revolver 38 spesial untuk uji balistik dan mesin uji bending. Setelah resin dipanaskan selama 1 menit, campur dan aduk bersama silikon karbid selama kurang lebih 1 menit setelah itu dicampur katalis dan siap dituang kedalam cetakan. Hasil pengujian balistik/tembak material rompi anti peluru pada variasi struktur serat rami spesimen anyaman dengan jarak tembak $10 \mathrm{~m}$ dan Deformasi Peluru rata-rata 3,85 tidak mengalami pecah/tertembus peluru ditunjukkan dengan deformasi peluru tertinggi 4,5 mm dibandingkan rata - rata deformasi peluru spesimen lurus $(2,6 \mathrm{~mm})$, acak $(2,47 \mathrm{~mm})$ dan miring $45^{\circ}(2,1 \mathrm{~mm})$ yang mengalami pecah/tertembus peluru. Pada pengujian bending variasi struktur serat rami anyaman rata - rata kekuatan bending nya 1,259 kgf/mm². Variasi struktur serat rami lurus rata - rata kekuatan bendingnya $2,447 \mathrm{kgf} / \mathrm{mm}^{2}$. variasi struktur serat rami acak spesimen rata-rata kekuatan bending nya adalah $1,428 \mathrm{kgf} / \mathrm{mm}^{2}$. variasi struktur serat rami miring $45^{\circ}$ rata-rata kekuatan bending nya adalah $1,070 \mathrm{kgf} / \mathrm{mm}^{2}$.
\end{abstract}

Kata kunci: epoksi, matrik, serat rami komposit, uji balistik, uji bending

\section{PENDAHULUAN}

Beberapa tahun ini di Indonesia perkembangan rekayasa material bahan telah mengalami kemajuan, banyak produk yang di hasilkan dari rekayasa material komposit di antaranya adalah body armour. Perkembangan armour ini adalah tuntutan perkembangan senjata api yang semakin pesat. Untuk itu di carilah solusi untuk membuat material komposit tahan peluru yang mampu mengurangi sebanyak mungkin lontaran energi kinetik peluru. Anggapan bahwa pemakai rompi anti peluru dapat terhindar sepenuhnya dari cidera yang di hasil kan oleh tembakan adalah salah. Peluru ditekankan sekali lagi, bahwa fungsi utama rompi peluru adalah untuk menahan peluru. Sehingga peluru tidak sampai masuk kedalam tubuh pemakai rompi anti peluru, tidak jarang akibat tekanan yang ditimbulkan peluru tadi pemakai rompi anti peluru akan menderita luka memar dan bahkan patah tulang.

Keunggulan serat rami dibanding dengan fiber glass adalah komposit rami lebih ramah lingkungan karena mampu terurai secara alami dan harganya pun lebih murah di banding fiber glass. Rami merupakan tanaman yang memiliki kandungan serat yang tinggi, dan mempunyai kelebihan serat lebih panjang, kekuatan lebih besar daya serap air juga lebih besar. Namun saat ini pemanfaatan rami di Indonesia hanya sebatas bahan dasar pembuatan pakaian dan kertas. Tentunya akan mempunyai nilai lebih jika serat tersebut dapat digunakan untuk menggantikan serat non alam (fiber glass) yang selama ini masih diimpor dari luar negeri sebagai penguat material komposit. Kekurangan serat rami yaitu seratnya kasar dan daya mulur lebih rendah dibandingkan serat kapas (Edy Yusuf, 2008).

Epoksi merupakan suatu polimer thermoset yang terbentuk dari hasil reaksi resin dan hardener/pengeras. Memiliki keuntungan mudah dibentuk dan tahan korosi tapi mempunyai kelemahan yaitu relatif getas. Silicon Carbide (SiC) merupakan material keramik yang harganya relatif mahal karena untuk memproduksinya diperlukan banyak energi dan bahan campuran. Campuran untuk membuat silicon carbide antara lain pasir silika, karbon, besi posfat, dan nitrium silikat. 


\section{LANDASAN TEORI}

Pengertian serat menurut kamus besar bahasa Indonesia adalah suatu material yang perbandingan panjang dan lebarnya sangat besar dan molekul penyusunnya terorientasi terutama ke arah panjang.

Serat pada umumnya di bagi menjadi 2 kelompok yaitu serat alam dan serat buatan. Serat alam, serat alam terbagi dalam 3 kategori besar, serat yang berasal dari tumbuhan, serat yang berasal dari hewan dan materi dan anorganik. Kapas, rami, kapuk adalah beberapa contoh serat alam yang berasal dari tumbuhan, sedangkan wol dan sutera serat yang berasal dari hewan, sementara serat asbes adalah contoh serat yang berasal dari material anorganik (Abdul latief sulam, 2008).

\section{Tanaman Rami}

Tanaman rami (Boehmeria nivea) merupakan tanaman tahunan yang mudah tumbuh dan berkembang baik di daerah tropis. Bentuk serat rami bervariasi dari $2,5 \mathrm{~cm}$ sampai dengan $50 \mathrm{~cm}$ dengan panjang rata - rata $12,5 \mathrm{~cm}$ sampai $15 \mathrm{~cm}$. Diameternya berkisar antara 25 sampai dengan 75 dengan rata - rata $30-50$. Bentuk memanjang serat rami seperti silinder dengan permukaan bergaris - garis dan berkerut membentuk benjolan kecil, sedangkan irisan lintang berbentuk lonjong memanjang dengan dinding sel yang tebal (Industri Teksti, 2014).

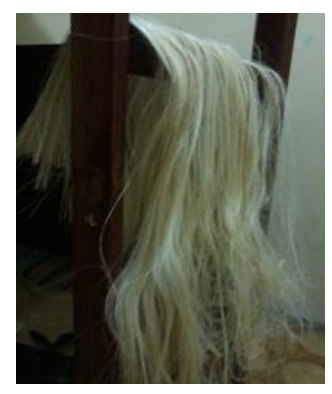

\section{Gambar 1. Serat rami yang sudah melewati proses degumming.}

Tujuan proses degumming adalah untuk menghilangkan sebanyak mungkin senyawa gum yang masih ada di antara helaian serat rami. Pada serat rami kasar kandungan gum nya berkisar Proses degumming biasanya dilakukan dengan cara memasak antara 25-30\% china grass dengan larutan alkali selama beberapa jam. Cara degumming ada beberapa macam, antara lain menggunakan $\mathrm{NaOH} 0,5 \%$,
Na2C03, Na-tripolifosfat $3 \%$ serta bahan pembasah (teepol) sebanyak $3 \%$.

\section{Struktur Penyusunan Serat Rami}

Hal lain dari pemanfaatan serat rami adalah mengurangi pencemaran lingkungan (biodegradability) karena biasanya tidak terpakai setelah dipanen dan faktor-faktor ekonomis yaitu ketersediaan bahan baku serat alam (serat rami) yang cukup melimpah disekitar kita. Untuk memperkuat struktur material bahan uji maka akan dilakukan variasi struktur dari serat rami tersebut. Ada 4 macam variasi struktur yang akan diuji balistik dan bending, diantaranya adalah :

- Variasi struktur serat rami anyaman.

- Variasi struktur serat rami vertikal.

- Variasi struktur serat rami acak.

- Variasi struktur serat rami miring dengan sudut kemiringan $45^{\circ}$.
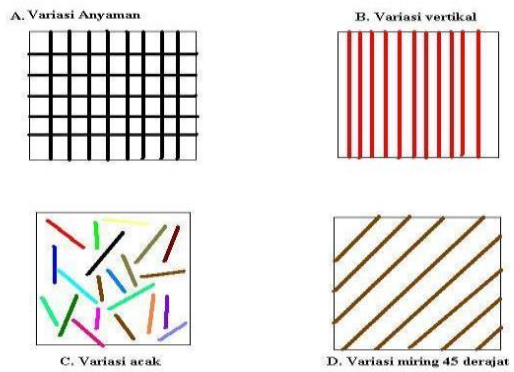

\section{Gambar 2. Variasi struktur serat rami yang akan diuji}

Dalam variasi anyaman serat rami yang di gambarkan pada Gambar 2 menggunakan pola anyaman basket. Model anyaman tersebut memiliki struktur plain weave yang relative sederhana namun kuat dalam menerima tekanan (Rafiudin Syam 2012). Orentasi arah serat rami, ukuran dan bentuk serta material serat adalah faktor - faktor yang mempengaruhi sifat mekanik dan laminat.

\section{Pengertian Komposit}

Kata komposit (composite) merupakan kata sifat yang berarti susunan atau gabungan. Komposit berasal dari kata kerja "to compose" yang berarti menyusun atau menggabung. Material komposit terdiri dari dua buah penyususn yaitu filler (bahan pengisi) dan matriks. Material komposit mempunyai beberapa keuntungan selain berbobot ringan, tahan korosi juga mempunyai kekuatan dan 
kekakuan yang baik serat dalam pembuatanya biaya sangat murah (Arumaarifu, 2010).

\section{Silicon Carbide (SiC)}

Silicon carbide dibuat dari bahan baku utama pasir silika dan karbon. Silikon karbida dengan struktur tetrahedral dari karbon dan atom silikon dengan ikatan yang kuat dalamkisi Kristal. Hal ini menghasilkan bahan yang sangat keras dan kuat. Butiran silikon karbida tahan terhadap asam atau basa serta garam sampai $1800-1900^{\circ} \quad$ (Daud Simon Anakottapary, 2010).

\section{METODOLOGI PENELITIAN}

Penelitian ini menggunakan metode eksperimental, yaitu dengan membuat spesimen dari campuran resin epoksi dan hardener sebagai penguat dengan $\mathrm{SiC}$ sebagai bahan matriks dan serat rami sebagai penguat komposit. Penelitian ini mencari pengaruh penambahan $\mathrm{SiC}$ dan variasi struktur serat rami komposit matrik epoksi terhadap kekuatan uji balistik dengan jarak tembak $10 \mathrm{~m}$ menggunakan pistol revolver 38 spesial dan uji lengkung kekuatan bending. Untuk perbandingan campuran adalah $70 \%$ epoksi dan $30 \%$ penguat, lalu menyiapkan variasi serat rami yaitu anyaman, horizontal, acak dan miring $45^{\circ}$.

Bahan yang digunakan dalam penelitian ini adalah Resin epoksi tipe General Purpose (Bisphenol A-Epichlorohydrin) dan Hardener tipe General Purpose (Polyaminoamide), Silikon Karbida dengan ukuran 120 dan Serat rami. Alat yang digunakan dalam penelitian ini yaitu: gunting, cetakan spesimen dengan ukuran untuk cetakan pengujian bending adalah $5 \mathrm{~cm} \mathrm{x}$ $19 \mathrm{~cm}$ dan cetakan pengujian balistik $20 \mathrm{~cm} \mathrm{x}$ $20 \mathrm{~cm}$, mixer, grease, gelas ukur, jangka sorong, pistol revolver 38 spesial untuk uji balistik dan mesin uji bending. Setelah resin dipanaskan selama 1 menit, campur dan aduk bersama silikon karbid selama kurang lebih 1 menit setelah itu dicampur katalis dan siap dituang kedalam cetakan.

\section{HASIL DAN PEMBAHASAN \\ Pengujian Balistik}

Pada pengujian balistik menggunakan pistol revolver 38 spesial dengan jarak $10 \mathrm{~m}$ sesuai dengan standar NIJ 0108.01. Data dari hasil pengujian balistik meliputi deformasi peluru dari tinggi awal peluru sampai ukuran peluru ketika mengenai spesimen dan tembus atau tidak nya spesimen ketika terkena peluru. Pistol revolver 38 mempunyai kecepatan maksimum peluru $259 \mathrm{~m} / \mathrm{s}$, berat proyektil10,2g dan berdiameter $9 \mathrm{~mm}$.

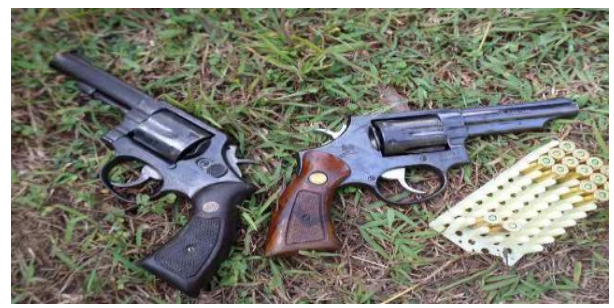

Gambar 3. Pistol Revolver 38 spesial

Dengan menggunakan rumus untuk menghitung Deformasi peluru yaitu :

$D P=h_{0}-h_{1}$

Dimana : $D P$ : Deformasi Peluru

$\mathrm{h}_{0}$ : Tinggi awal peluru

$\mathrm{h}_{1}$ : Tinggi peluru setelah penetrasi

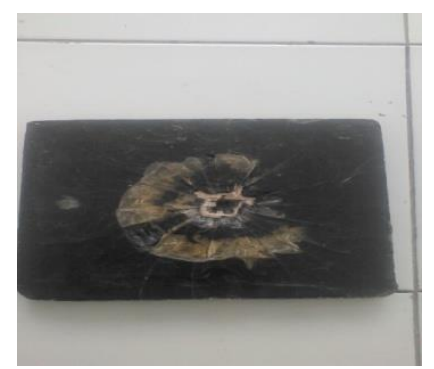

Gambar 4. Spesimen setelah dilakukan uji balistik

\section{Uji Balistik}

- Uji Balistik

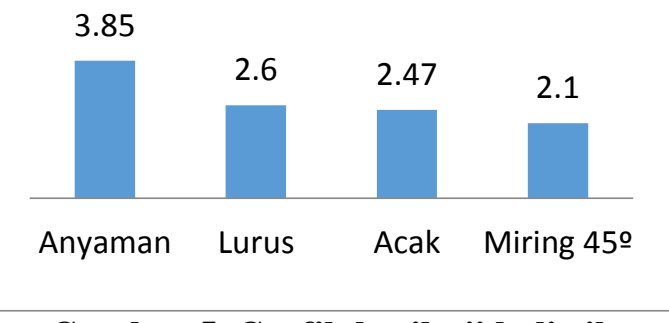

Gambar 5. Grafik hasil uji balistik

Dari tabel dan grafik hasil pengujian balistik menunjukan deformasi peluru tertinggi terjadi pada spesimen 1 variasi struktur serat rami anyaman yaitu sebesar $3,85 \mathrm{~mm}$. 


\section{Pengujian Bending}

Pada pengujian bending menggunakan mesin merk Torsee's Universal Testing Machine, Type $=$ AMU $-5-$ DE, Produksi = Tokyo, Japan Tahun 1987. Ukuran spesimen mengacu pada standar ASTM D 79002 dimensi spesimen pengujian span (jarak antara titik tengah beban dengan penyangga spesimen uji), panjang total, lebar dan tebal. Dengan mengacu pada kondisi pembebanan yang berpusat di tengah material uji yang disebut dengan "Three Point Bending".

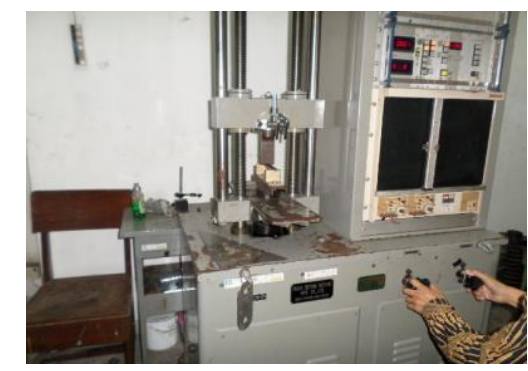

\section{Gambar 6. Mesin uji bending}

Rumus yang dipakai untuk mengetahui kekuatan beban maksimum yang diterima oleh spesimen adalah :

$\sigma_{f}=\frac{3 P L}{2 b h^{2}}$

Dimana :

$\sigma f=$ Kekuatan Bending $\left(\mathrm{Kg} f / \mathrm{mm}^{2}\right)$

$\mathrm{P}=$ Beban maksimum (Kgf)

$\mathrm{b}=$ Lebar dari benda uji $(\mathrm{mm})$

$\mathrm{h}=$ Tebal benda uji $(\mathrm{mm})$

$\mathrm{L}=$ Jarak antara penyangga $(\mathrm{mm})$

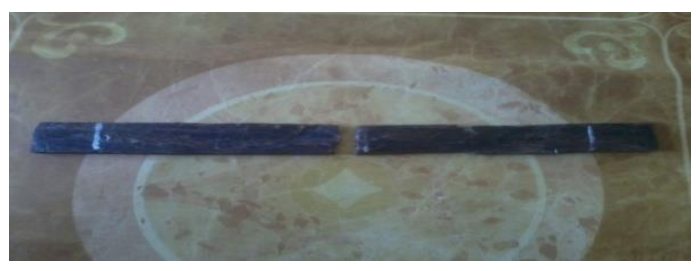

Gambar 7. Spesimen uji bending stelah pengujian bending

\section{uji bending}

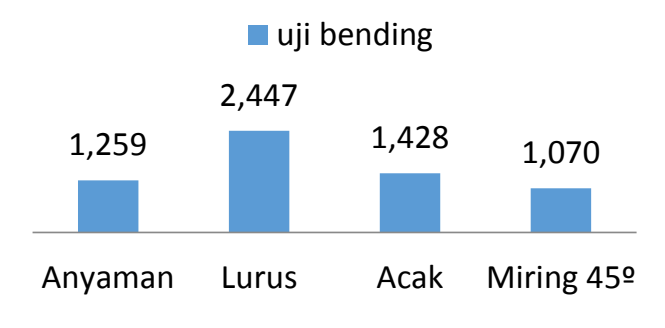

Gambar 8. Grafik hasil uji bending

Dari tabel dan grafik hasil pengujian bending menunjukan kekuatan bending tertinggi pada variasi struktur serat rami lurus spesimen 1 yaitu 2,447 $\left(\mathrm{Kgf} / \mathrm{mm}^{2}\right)$.

\section{KESIMPULAN}

Pada pengujian balistik hanya spesimen serat rami anyaman tidak tertembus peluru dan tidak retak dengan deformasi peluru sebesar 4,5 $\mathrm{mm}$ sehingga mampu dijadikan rompi anti peluru level 1 pada standar NIJ 0108.01.

Pada pengujian bending dengan menggunakan standar ASTM D790-02 didasarkan pada pembebanan titik benda uji yang terletak pada tiga titik atau yang disebut dengan "Three Point Bending" maka didapat hasil beban maksimum yang paling besar terjadi pada variasi struktur serat rami lurus dengan rata - rata kekuatan bending 2,447 $\mathrm{Kgf} / \mathrm{mm}^{2}$.

\section{DAFTAR PUSTAKA}

Anonim, 2015, Pengertian Komposit, Available from URL

https://arumaarifu.wordpress.com/2010/0 2/04/apa-itu-komposit/

Abdul Latief, Sulam, 2018, Teknik Pembuatan Benang dan Pembuatan Kain, Jakarta : Direktorat Pembinaan Sekolah Menengah Kejuruan.

Daud Simon Anakottapary, "Interaksi antara Proyektil dan Komposit Polimer diperkuat Butiran Silikon Karbid (SiC) dan Serat Karbon pada Pengujian Balistik" Jurnal Ilmiah Teknik Mesin, Oktober 2010: hal. 101.

Edy Yusuf, "Pengaruh Fraksi Volume Dan Orientasi Serat Terhadap Kekuatan Tarik Bahan Komposit Serat Rami Kontinyu Bermatrik Polyester" Jurusan Teknik Mesin Fakultas Teknik, 2010; hal. $1-2$. 
Rafiudin Syam, "Analisis Sifat Mekanis Tenunan Serat Rami Jenis Basket Tipe s 3/12 Dengan Matriks Epoksi Resin (Kekuatan Bending)" Group Teknik Mesin, Desember 2012; hal: 3.

Sofyan Djamil, "Sifat Balistik Metal Matrix Composite Dengan Woven Metode Satin Twilled Weave" Program Studi Teknik Mesin Fakultas Teknik Universitas Tarumanegara Jakarta, 2011; hal. 1. 